\title{
Investigation of Roll-to-Roll Gravure Printing for Printed Electronics with Fine Features
}

\author{
S.H. Chen ${ }^{1}$, S.T. Pua ${ }^{1,2}$, Z.W. Zhong ${ }^{2}$, X.C. Shan ${ }^{1}$ \\ 1. Singapore Institute of Manufacturing Technology, 73 Nanyang Drive, Singapore \\ 2. Nanyang Technological University, 50 Nanyang Avenue, Singapore \\ E-mail: mzwzhong@gmail.com,mzwzhong@ntu.edu.sg; xcshan@simtech.a-star.edu.sg
}

Received: 30 July 2020; Accepted: 24 August 2020; Available online: 20 September 2020

\begin{abstract}
Gravure printing is known to be cost competitive in manufacturing of printed electronic devices due to its capability to mass produce at lower costs. Current standard of gravure printed feature sizes is in a range of around $50 \mu \mathrm{m}$ down to sub-10 $\mu \mathrm{m}$, predominantly through small scale setups and specialized engraving. However, reliance on gravure cell design limits the scalability of printing over a large area due to the setup cost. In this study, ink viscoelastic behavior was modified to improve replication of gravure printed features over a large printing area of $300 \mathrm{~mm}$ web-width without a reduction in gravure cell dimension. Fine lines were printed using a high viscosity ink with a good replication of the nominal line width. Control over the printed features was performed through the variation of printing speed and the alteration of ink viscosity. The effects of ink viscosity and printing speed on the printed ink particle distribution and size were also examined. New methodologies of characterizing ink transfer were also developed to help understand the ink transfer processes: mass transfer and particle transfer. A deeper understanding of the thixotropic effect and shear recovery behavior of inks was achieved through simulations of shearing conditions.
\end{abstract}

Keywords: R2R printing; Gravure printing; Shear recovery; Thixotropy; Mass transfer; Particle transfer; Pickout; Silver nanostructure.

\section{Introduction}

Nanoimprint lithography has emerged for printed electronics with high resolution patterning and throughput, and low costs [1-5]. Printing of electronics is an alternative approach to the conventional electronics manufacturing of silicon devices. Printed electronics [6] is achieved through the application of functional inks onto flexible substrates through the use of printing technologies. Typical products of printed electronics include thin film transistors, solar cells and radio frequency identification tags. To achieve economical mass production of the printed electronics products, roll-to-roll (R2R) processing is necessary due to its scalability, and direct gravure printing is often preferred over other printing technologies due to its stability and reliability [7].

$\mathrm{R} 2 \mathrm{R}$ is employed for production of flexible, high-volume printed electronics. Inkjet printing, gravure printing, screen printing [8] and flexographic printing [9] may be conducted for printed electronics. Flexographic printing and gravure printing are more suitable for continuous R2R, large format and high speed printing [4,5]. The properties of the resin, mold and film can establish the profiles of the embossed microstructures $[10,11]$. The polymer can affect the embossing process [12,13]. Flexible molds made from a polymer substrate may be employed [14].

Direct gravure printing is a printing process where inks are transferred from engraved cells on a rotating gravure roller onto the surface of a moving substrate, followed by thermal curing. Key efforts in gravure printing research have been placed on reducing printed feature sizes and concurrently ensuring replication quality of features. A key application where small features are required is the printing of conductive traces in a dense printed circuitry. The major issue faced when printing thin line widths is the loss of conductivity over a large area. Hence, it is of keen interest to print thin and conductive lines concurrently.

The thinnest conductive trace reported for gravure printing was sub-10 $\mu \mathrm{m}$ fabricated using a roll-to-plate (R2P)

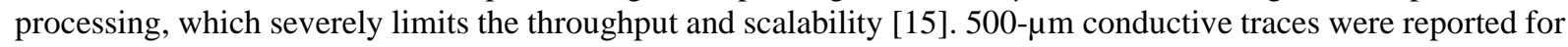
small-area R2R gravure printing; however such achievements of reduction in feature sizes were reliant on the engraving [16] and etching [15] capabilities of gravure cells, leading to increased fabrication costs of gravure rollers. Various printing parameters can also affect the printed line widths and conductivity of the conductive traces. These parameters include ink viscosity, printing speed, cell geometry, printing pressure, wrap angle and substrate 
tension. However, previous studies had shown that variations in wrap angle $[17,18]$ and web tension [19] were of less significance in comparison to other printing parameters. On the other hand, ink viscosity [18,20-24], printing pressure [25,26], cell geometry $[18,19,27,28]$ and speed ratio $[18,29]$ (ratio of substrate speed to gravure roller speed) have been reported to give substantial effects on ink transfer, conductivity and printed line width.

Therefore, it is of keen interest to investigate the shearing and recovery behaviors of inks to achieve thin conductive traces in gravure printing. This negates the need for costly and time consuming roller fabrication processes. Furthermore, studies of the transfer and distribution of conductive ink particles in the printed lines would allow a greater insight into the effects of ink shearing behavior on the performance of the printed lines.

\section{Research gap}

Ink shearing behavior in gravure printing can be studied in two major areas, i.e. viscosity and thixotropy. Previous studies on the effects of viscosity reported that using viscous inks gave a greater film thickness and higher ink transfer from gravure cells to the substrate [18]. It was also reported that using a high viscosity ink produced better print quality and high conductivity [23]. However, a high viscosity ink presents the difficulty in proper doctoring, which may lead to residual ink outside of the intaglio surfaces. It could be resolved by increasing the wiping speed [30]. On the other hand, a study conducted using a low viscosity ink produced a thin line width [15]; this could be attributed to the lower solid contents, or low ink transfer ratio resulting in less ink available to spread over the substrate. However, a low viscosity ink led to printing defects [16] that would not be present with a higher viscosity ink. The literature on gravure printing of conductive traces has thus far focused on the viscosity while ignoring the fact that the inks used are usually an emulsion or suspension of solvent, binder and particles, which do not shear homogeneously. There is a huge research gap in the quantification of the ink transferred in terms of mass, number of particles and the effects of the ink shearing behavior on both. The number of particles transferred can strongly affect the percolation of the printed conductive traces, thus leading to a decrease in conductivity, and it needs to be quantified.

Thixotropy shares a similar behavior with that of the polymer memory effect [31], in which viscosity recovers over time to an equilibrium. It was also reported that a thixotropic ink would be an ideal ink type for gravure printing [32]. By introducing greater thixotropic properties to the ink, the spreading of line widths could be curtailed by restoring ink viscosity to equilibrium at an accelerated rate. It is therefore crucial to induce thixotropy in inks, which may lead to a reduction in line width while increasing the percolation simultaneously.

In this study, the effect of ink shearing behavior on printed line width was thoroughly investigated through a design of experiments with 2 parameters, i.e. printing speed and ink viscosity. The viscosity alterations were achieved using a plasticizer and keeping the particle size and quantity constant. The printed conductive traces were characterized and a theoretical model that quantifies the mass and particle transferred is presented. An attempt to achieve a 1:1 replication of line width to cell is demonstrated with ink viscosity engineering. The simulated shearing process was performed in a rotational rheometer to study the shearing and thixotropy effect of plasticizers induced viscosity variations. Finally, the authors offer a strategy using high aspect ratio nanostructures to plasticize conductive inks for inducing thixotropy and maintaining percolation simultaneously.

Additionally, it is crucial that the effects of the ink shearing behavior on the ink transfer process are characterized accurately. Ink transfer was often characterized using pick-out, as shown in Equation (1), in numerous papers $[18,27,29]$. It uses the measured film thickness $\left(\mathrm{H}_{\mathrm{T}}\right)$, the cell volume per unit area $\left(\mathrm{V}_{\mathrm{c}}\right)$, and the speed ratio $(\mathrm{S})$ of the substrate speed to the gravure roller speed.

$$
\varphi=\frac{H_{T}}{V_{C}} S
$$

Pick-out would be able to characterize ink transfer for coating purposes, but this particular ratio does not account for actual empirical measurements of the fine printed features such as lines. It is, therefore, of importance to improve upon the accuracy of such characterization especially when fine features are involved, as the tolerance for deviation is extremely minute. In this study, the characterization of ink transfer shall be explored later in this paper, using newly suggested transfer ratios, namely mass and particle transfer ratios.

\section{Experiments}

Experiments were conducted using a $300 \mathrm{~mm}$ web-width R2R direct gravure printing machine that was developed in-house in Singapore Institute of Manufacturing Technology (SIMTech). The printing speed was operated between 2 and $7 \mathrm{~m} / \mathrm{min}$. The substrate was maintained at an operating tension of $2.7 \mathrm{kgf}$, while the curing temperature of the in-line oven was set at $130{ }^{\circ} \mathrm{C}$.

The stainless steel gravure roller was electroplated with copper, subsequently etched to form designed gravure 
cells, and finally coated with chromium. The gravure cells were of quadrangular shape and arranged in lines forming a $\pm 45^{\circ}$ cross mesh; the cell width of the pattern was $55 \mu \mathrm{m}$ while the cell depth was $13.5 \mu \mathrm{m}$. Its surface energy was measured to be $33 \mathrm{mN} / \mathrm{m}$. The rollers were prepared by cleaning with methyl ethyl ketone, isopropanol, acetone and de-ionized water before experiments.

The base ink used for printing was a silver paste ink (Asahi Chemical Co., Ltd.), which had an average particle size of $2 \mu \mathrm{m}$ and a viscosity of $14000 \mathrm{cP}$. The substrate used was polyethylene terephthalate (PET), which was physically treated to have an average surface energy of $39 \mathrm{mN} / \mathrm{m}$ for improvement in adhesion.

The ink was prepared by mixing uniformly in a planetary mixer before being poured into the ink tray. The ink was then picked up by the gravure rollers from the ink tray and doctored at the set printing speed. Ink was then transferred from the gravure cells onto the PET substrate, which was rolled along the impression roller. The printed substrate was then cured along the in-line oven and rolled back into a rewinding roll.

\section{Results and discussion}

\subsection{Ink viscosity alteration}

The alteration of ink viscosity is shown in Fig. 1. In this study, two formulations were used to investigate the effects of ink viscosities, i.e. $14000 \mathrm{cP}$ and $1000 \mathrm{cP}$. A binder compatible plasticizer was added in weight percentage related to the organic phase of the original ink.

Plasticizing of a base ink was chosen over the usage of different inks of varying viscosities, to negate the possible effects that ink particle sizes, binder, and solvent content may have on the shearing behavior of ink. Besides eliminating such rogue elements, plasticizing is preferred over dilution as dilution merely increases the inter-particle distances to decrease viscosity, which would cause ink thinning and reduction in contact amongst particles. However, over thinning of ink invariably causes printing defects such as ribbing and pinholes.

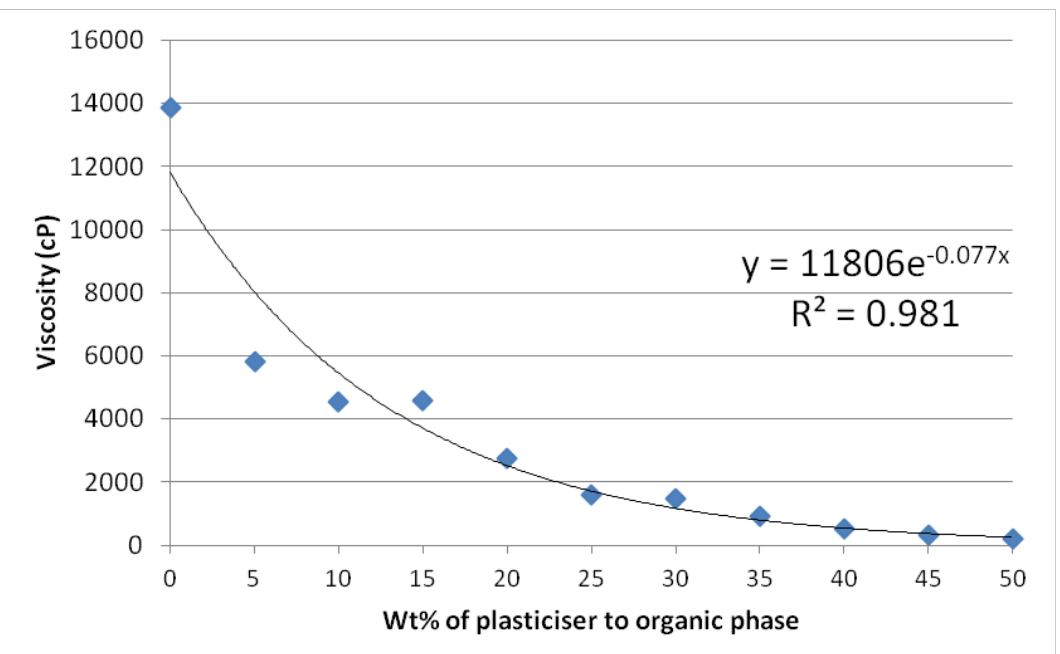

Fig. 1. Alteration of base ink viscosity through the addition of plasticizer with respect to organic phase of base ink.

\subsection{Effects of printing speed}

Due to the shear thinning nature of the ink, an increase in printing speed reduced both the printed line width and film thickness. This trend could be observed in the prints using both the $14000 \mathrm{cP}$ and $1000 \mathrm{cP}$ inks as shown in Figs. 2 and 3. The observed trend was due to shear thinning of the ink at higher speeds. Thus, viscosity of the ink was lowered, and this reduced ink transfer and directly led to less ink volume printed. This result also agreed with a previous study [33].

Using a scanning electron microscope (SEM) and the cross sectional areas of the printed lines, it could be observed that printing at higher speeds distributed the silver particles further apart, as shown in Fig. 4. For a unit area, it could also be observed that the inhomogeneity of the printed lines increased (i.e. the amount of the printed binder increased at higher printing speeds). Heterogeneous distribution of silver particles and binder could be explained by the shear thinning mechanism of the ink. The configuration of silver particles and binder particles at higher printing speeds agrees with the mechanism of colloids in a shear thinning viscoelastic fluid [34].

However, printing at higher speeds is inclined to result in printing defects such as breakage of lines and pinholes, which could be observed in Fig. 5. This was due to the nature of the ink; the ink shear thinned excessively at high speeds and reduced ink transfer. 

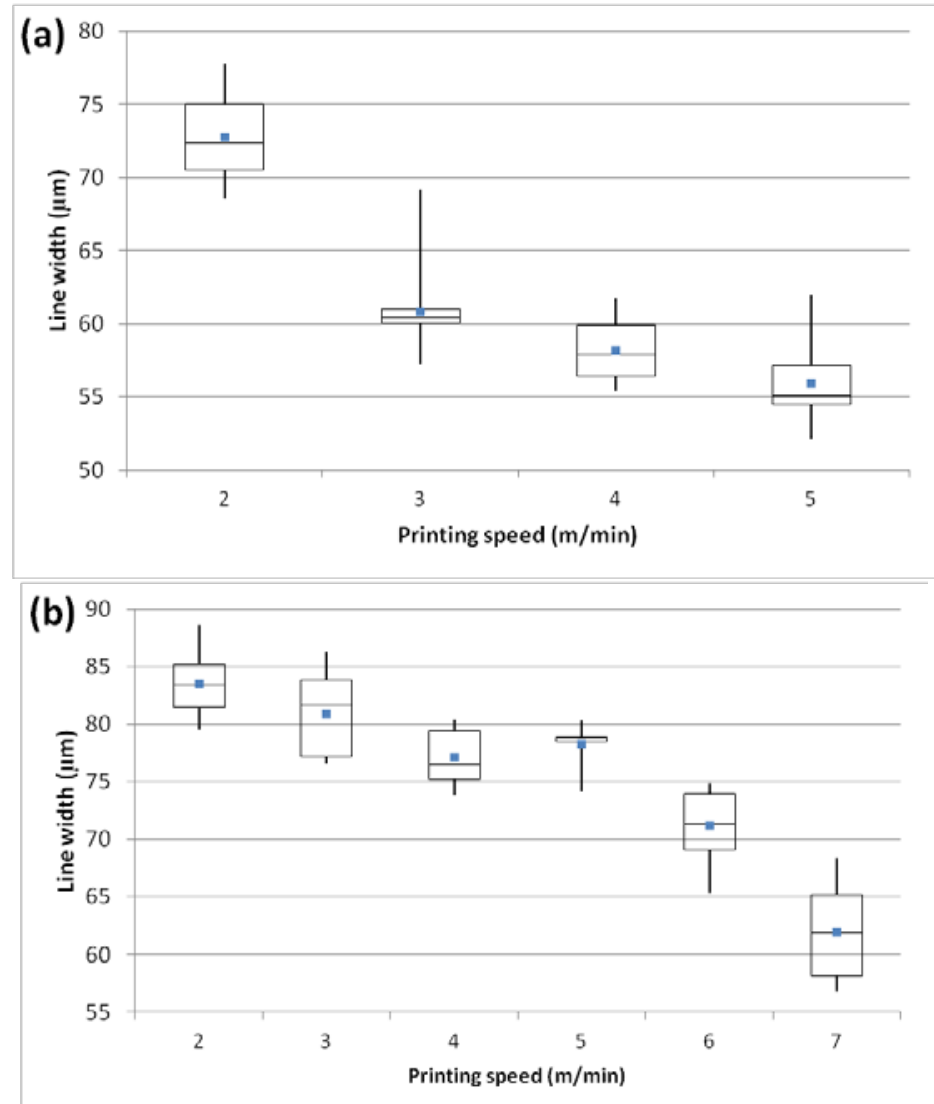

Fig. 2. Reduction in printed line width with increasing printing speed. (a) Results shown using $14000 \mathrm{cP}$ ink printed at 2 to $5 \mathrm{~m} / \mathrm{min}$. (b) Results shown using $1000 \mathrm{cP}$ ink printed at 2 to $7 \mathrm{~m} / \mathrm{min}$.

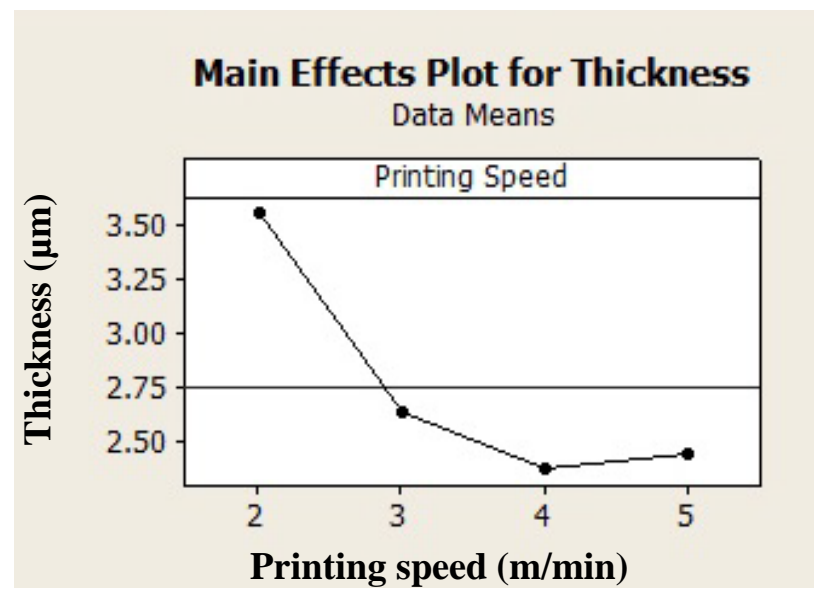

Fig. 3. Main effect plot of the printed film thickness printed from 2 to $5 \mathrm{~m} / \mathrm{min}$ using $14000 \mathrm{cP}$ ink.

\subsection{Effect of ink viscosity}

From Fig. 2, it was observed that using an ink of a higher viscosity significantly reduced the printed line width, indicating that the ink reduced the spread over the substrate. Furthermore, replication of the nominal cell width of $55 \mu \mathrm{m}$ was achieved at $5 \mathrm{~m} / \mathrm{min}$ using the $14,000 \mathrm{cP}$ ink. It was noted that the two curves of the $14,000 \mathrm{cP}$ ink and $1,000 \mathrm{cP}$ ink diverges with increasing printing speeds.

It was also observed that using an ink of a higher viscosity produced better line uniformity due to a reduction in the mensicus height as seen from Fig. 6. This result agreed with a previous study reporting line uniformity [33]. This could be due to a higher shear recovery, which would be explored later in section 4.5.

The difference in silver particle sizes was also observed by using an SEM in the cross sectional images of the printed lines. The results could be observed in Fig. 7. Printed at $2 \mathrm{~m} / \mathrm{min}$, the silver particles printed on the substrate using the $14,000 \mathrm{cP}$ ink were, on average, greater in size, compared to that using the 1,000 cP ink. This could be 
due to the higher viscous force present in the higher viscosity ink; higher viscous forces could drag bigger particles from the gravure cell onto the subtrate.

As seen from Fig. 4 and Fig. 7, the transfer and distribution of the conductive ink particles are varied when subjected to different parameters. As these particles determine the functionality of the printed features, it is worth investigating the particle transfer ratio as it provides a better understanding in the essential conductive element transfer in bulk ink transfer.

(a)

(b)
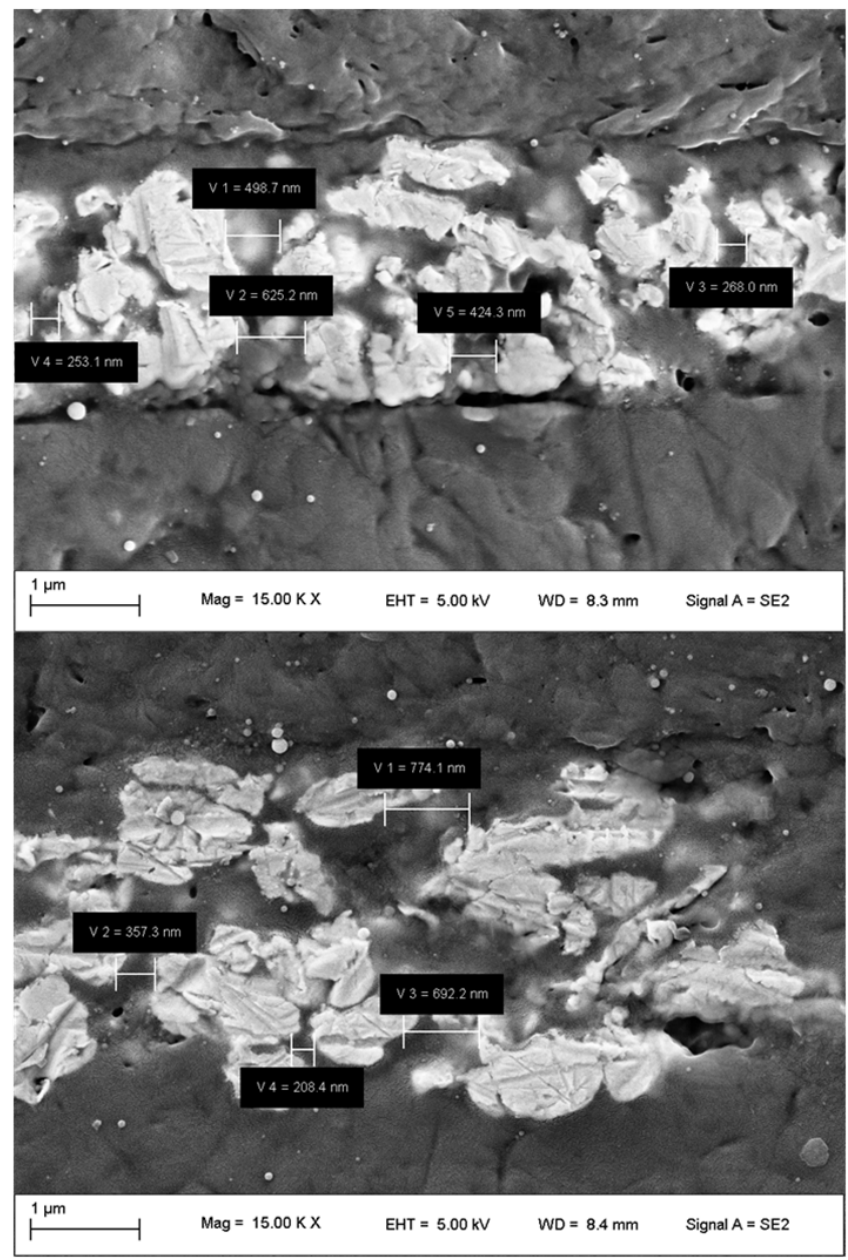

Fig. 4. SEM images of cross sectional area of lines printed at different speeds, displaying the difference in particle distribution. (a) Cross sectional area of line printed at $2 \mathrm{~m} / \mathrm{min}$ with $1000 \mathrm{cP}$ ink. (b) Cross sectional area of line printed at $4 \mathrm{~m} / \mathrm{min}$ with $1000 \mathrm{cP}$ ink.

(a)

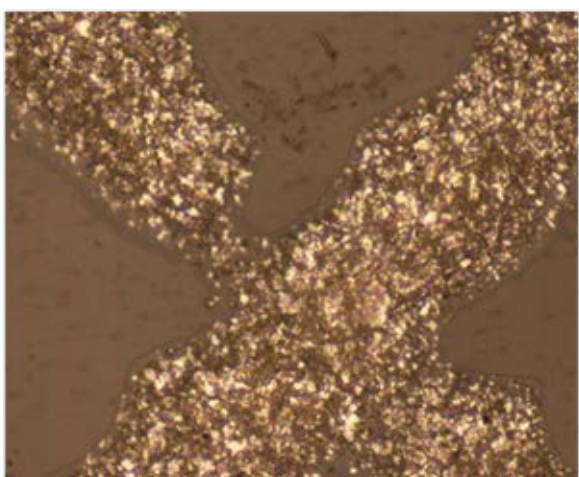

(b)

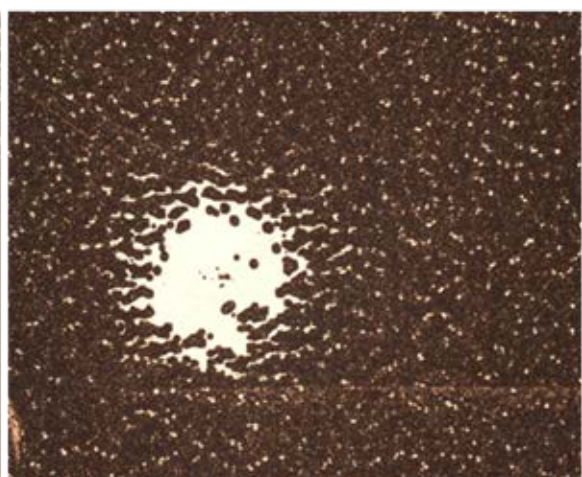

Fig. 5. Printing defects due to excessive shear thinning as a result of high printing speeds. (a) Breakage of line and (b) Pinhole formation 
(a)

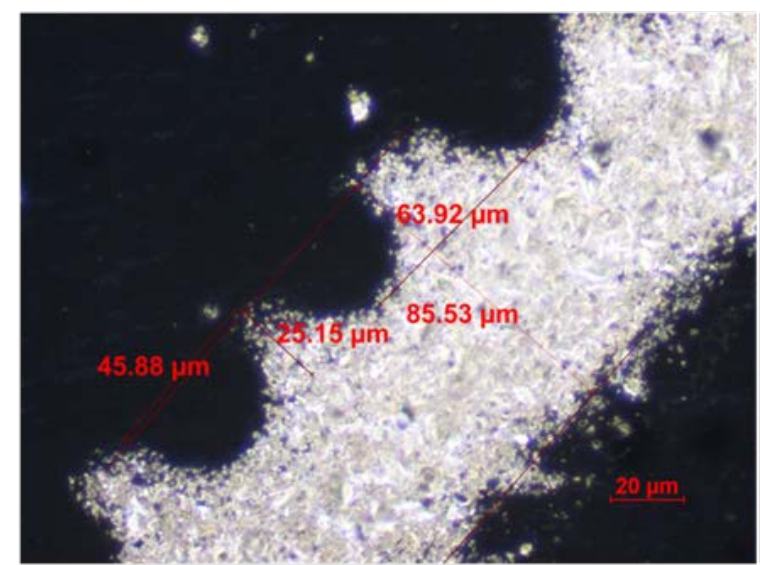

(b)

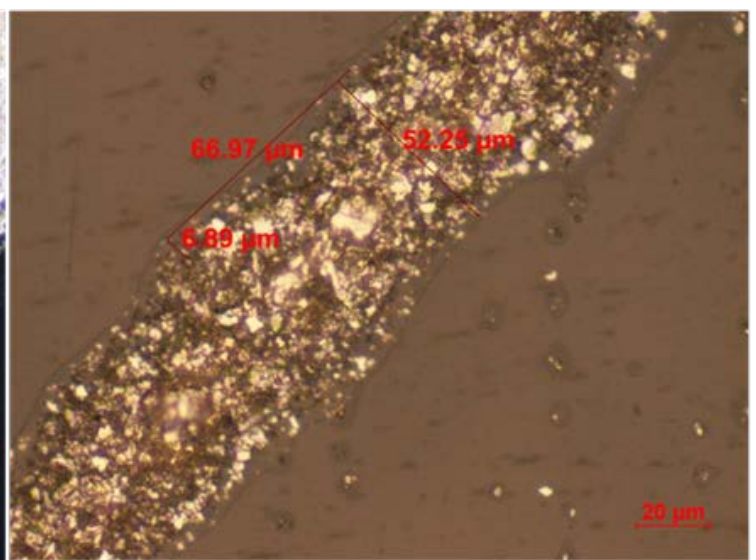

Fig. 6. A comparison of microscopic images of lines printed at $5 \mathrm{~m} / \mathrm{min}$, showing a difference in both line width and line uniformity. (a) Line printed with 1,000 cP ink. (b) Line printed with 14,000 cP ink.

(a)

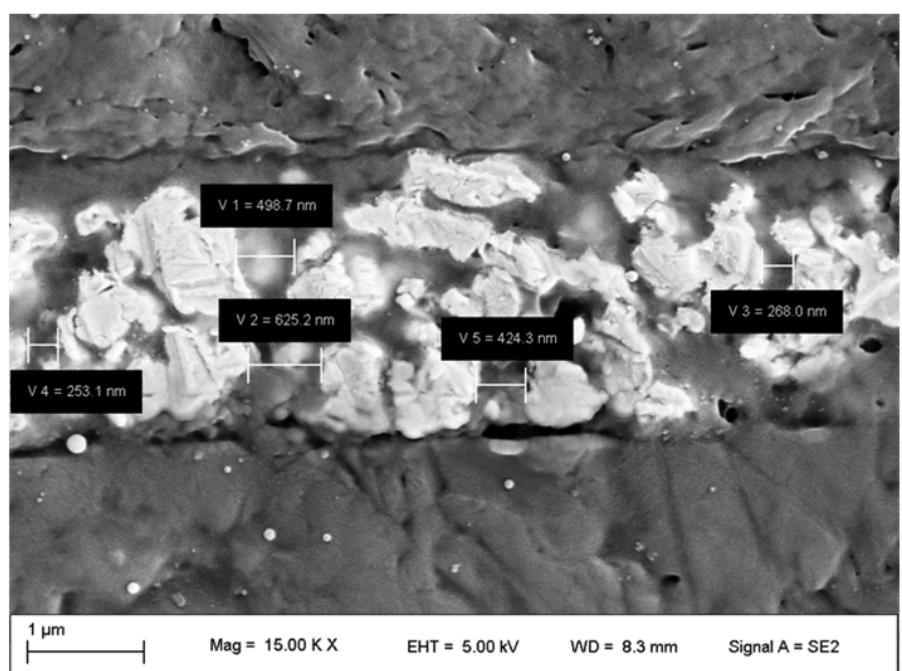

(b)

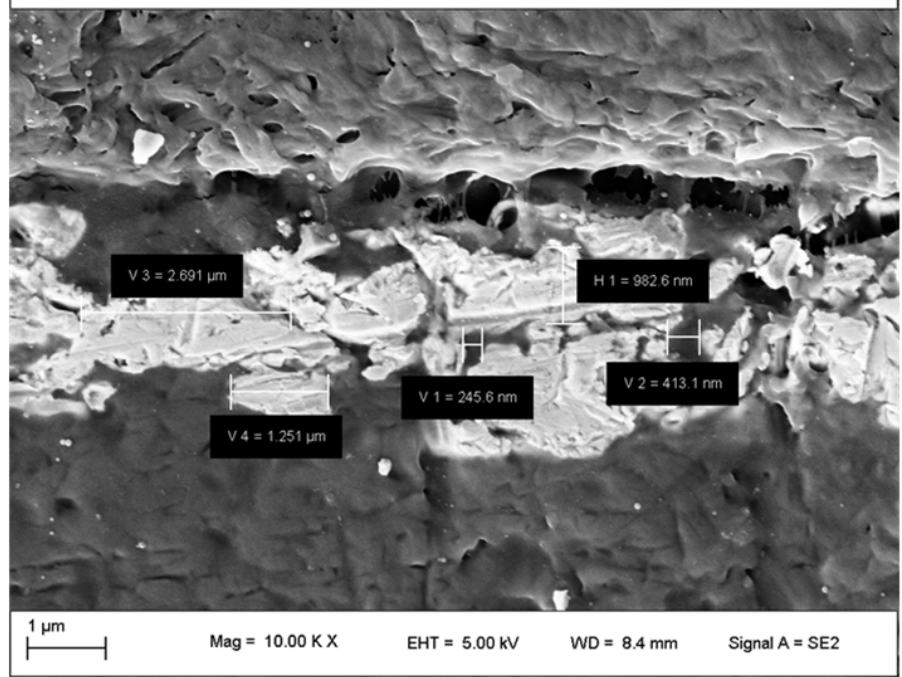

Fig. 7. SEM images of cross sectional areas of lines printed using inks having different viscosities, displaying the difference in particle size. (a) Cross sectional area of a line printed at $2 \mathrm{~m} / \mathrm{min}$ with 1,000 cP ink. (b) Cross sectional area of a line printed at $2 \mathrm{~m} / \mathrm{min}$ with $14,000 \mathrm{cP}$ ink.

\subsection{Ink transfer modeling}

As an alternative to pick-out, the mass transfer ratio (M) was proposed in this study. It is the ratio of the printed 
wet mass of a segment to the wet mass of ink in the segment. The said segment is shown in Fig. 8. The densities of the wet ink $\left(\mathrm{r}_{\mathrm{w}}\right)$ and cured $\left(\mathrm{r}_{\mathrm{d}}\right)$ ink were measured.

As shown in Fig. 8, a segment of gravure cells was used as a reference where the total volume of the ink in the segment $\left(\mathrm{V}_{\mathrm{t}}\right)$ equates to the sum of the volumes of the gravure cells. Correspondingly, this segment would be reflected onto the printed substrate, in which the film thickness of the segment (T), line width (LW), and printed segment length $(L)$ would be measured. The void area $\left(A_{v}\right)$ due to meniscus formation would be taken into account. The product of the net printed area and film thickness would be tabulated as the net printed volume of the segment $\left(\mathrm{V}_{\mathrm{s}}\right)$ as shown in Equation (2).

$$
V_{s}=\left[(L \cdot L W)-A_{v}\right] \cdot T
$$

To convert a cured segment into a printed but wet segment, a factor (C) was used. The factor $\mathrm{C}$ was derived to be the ratio of the wet mass to dry mass of a given ink volume. Hence, the mass transfer ratio could be derived as Equation (3).

$$
M=\frac{V_{s} \cdot \rho_{d} \cdot C}{V_{t} \cdot \rho_{w}}
$$

Similar to the mass transfer ratio proposed above, the particle transfer ratio (P) utilized the approach of segmentation described earlier. Particle transfer ratio would be important as the silver particles are the conduit for the printed film. Hence, investigating the particle transfer ratio provides a better understanding into the essential conductive element transfer in bulk ink transfer.

Particle transfer ratio compares the amount of silver particles present in the dry mass $\left(\mathrm{N}_{\mathrm{d}}\right)$ of the printed substrate to the amount of silver particles present in the gravure cell volume $\left(\mathrm{N}_{\mathrm{w}}\right)$.

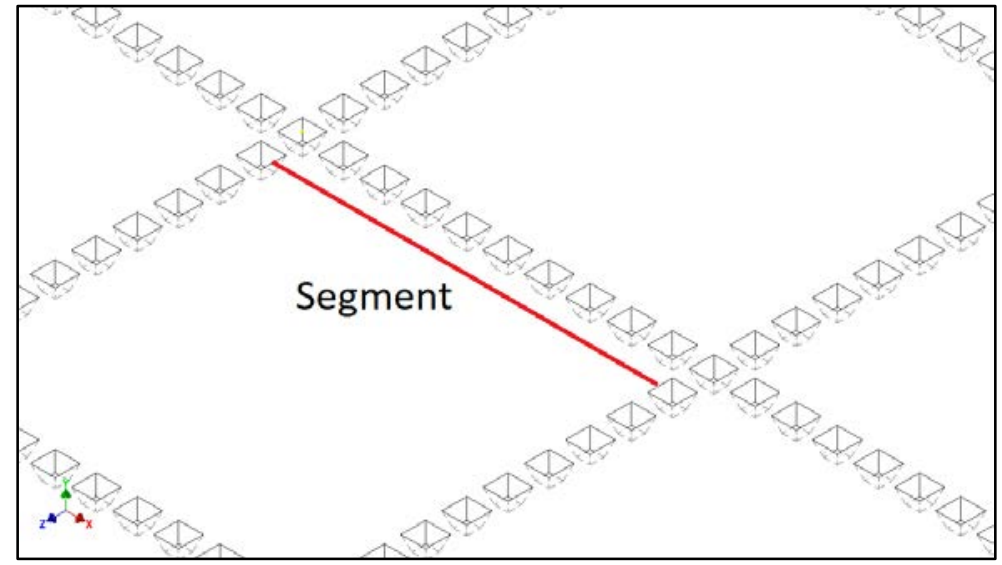

Fig. 8. Schematic of the gravure cells arrangement. Segment denotes the selection of cells (along the length of the line) used in ink transfer ratio calculations.

In addition to the variables used in mass transfer ratio, the particle transfer ratio makes use of atomic packing factor (APF) of silver, Avogadro number $\left(\mathrm{N}_{\mathrm{A}}\right)$, density of silver $\left(\mathrm{r}_{\mathrm{Ag}}\right)$, molar mass of silver $\left(\mathrm{M}_{\mathrm{Ag}}\right)$, mass ratio of silver in dry mass of printed patterns $\left(\mathrm{R}_{\mathrm{d}}\right)$, mass ratio of silver in the ink $\left(\mathrm{R}_{\mathrm{w}}\right)$, theoretical volume of a silver particle as a colloid $\left(\mathrm{V}_{\mathrm{p}}\right)$, assuming homogenous distribution of silver particles in the ink. The volume of a single silver atom $\left(\mathrm{V}_{\mathrm{a}}\right)$ was derived in Equation (4) based on a unit volume.

$$
V_{\mathrm{a}}=\frac{\mathrm{APF}}{\frac{\rho_{\mathrm{Ag}}}{\mathrm{M}_{\mathrm{Ag}}} \mathrm{N}_{\mathrm{A}}}
$$

The amount of silver atoms $\left(\mathrm{N}_{\mathrm{a}}\right)$ in a single silver particle was then subsequently derived in Equation (5).

$$
\mathrm{N}_{\mathrm{a}}=\frac{\mathrm{v}_{\mathrm{p}}}{\mathrm{V}_{\mathrm{a}}}
$$

The number of silver particles in the dry mass of a printed segment could be derived, using the mass ratio $R_{d}$, as shown in Equation (6). 


$$
N_{d}=\frac{V_{s} \cdot \rho_{d} \cdot R_{d}}{M_{A g}} \cdot N_{A} / N_{a}
$$

The number of silver particles in the wet mass of the gravure cells in a segment could be derived, using the mass ratio $\mathrm{R}_{\mathrm{w}}$, as shown in Equation (7).

$$
N_{w}=\frac{V_{t} \cdot \rho_{d} \cdot R_{W}}{M_{A g}} \cdot N_{A} / N_{a}
$$

The particle transfer ratio could then be derived as the ratio of number of silver particles in dry mass of a segment to the number of silver particles in the gravure cells of a segment as shown in Equation (8).

$$
P=\frac{N_{d}}{N_{w}}
$$

In Fig. 9, it could be observed that there is a substantial difference between pick-out and mass transfer ratio. The effect of printed line width holds a significant impact on the actual ink transfer. However, as the printing speed increases, the differences between the mass transfer ratio and pick-out minimizes and the two ratios eventually converge. This could be due to the fact that as printing speed increased, the printed area (used in mass transfer ratio) was reduced and approached the nominal cell area (used in pick-out); hence the effect of the printed area would be lessened and the two ratios converged. Therefore, mass transfer would be more accurate for analyzing printed line widths at lower printing speeds.

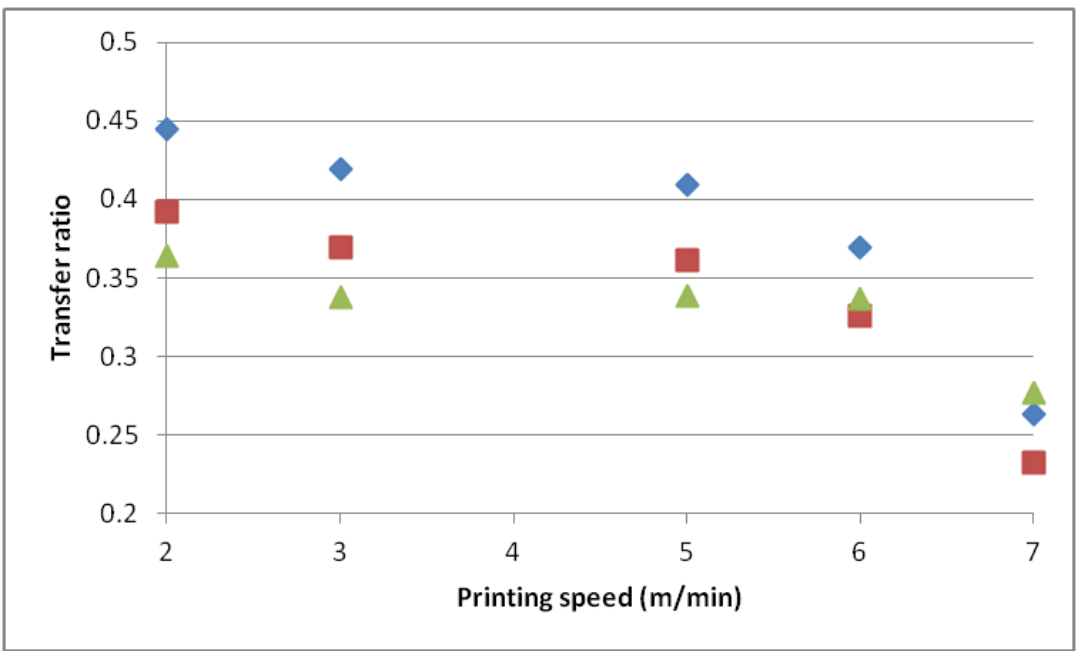

Fig. 9. Comparison of transfer ratios amongst pick-out (denoted by $\boldsymbol{\Delta}$ ), mass transfer (denoted by $\downarrow$ ) and silver particle transfer ratio (denoted by $\mathbf{~}$ ) using the $1,000 \mathrm{cP}$ ink. Data from $4 \mathrm{~m} / \mathrm{min}$ is omitted due to outliers.

The particle transfer ratio decreased as the printing speed increased; this was confirmed using the SEM cross sectional images in Fig. 4, where the silver particles appeared to be sparsely distributed at a higher printing speed.

Additionally, at printing speeds below $6 \mathrm{~m} / \mathrm{min}$, there was congruence between particle transfer ratio and pickout. This was due to the assumption of Newtonian flow for both. Particle transfer ratio omits the viscoelastic effect of the binder and solvent in the ink, and therefore this ratio represents a fully Newtonian transfer. Despite its inaccuracy at predicting non-Newtonian ink transfer, pick-out could be a simple alternative to quantify transfer characteristics for particle in such inks.

\subsection{Thixotropy effect}

In a set amount of time, the viscosity of the shear thinning ink returns to its equilibrium. However, it is the rate of return that is of greater interest in this study. Using the Anton Paar Rotational Rheometer (Physica MCR 301), a simulation of the gravure printing process was conducted to observe the behavior of the ink under different shearing conditions as listed below from (i) to (vi).

1) Ink preparation where the ink is stirred to homogenize the contents as uniformly as possible.

2) Ink reservoir where the ink is contained in the reservoir awaiting pick-up.

3) Ink pick-up where the ink is picked by the motion of the gravure roller into the gravure cells.

4) Ink transport where the ink is carried in the gravure cell subjected to the rotational motion of the gravure 
roller.

5) Ink transfer where the ink is transported onto the moving substrate from the cell.

6) Ink settlement where the ink settles on the moving substrate.

It could be observed from Fig. 10 that the two formulations of ink demonstrated similar behaviour, attributed to their similar ink content. Dips in viscosity were a result of the ink subjected to higher shear rates, while recoveries of viscosity were due to less or the total shear removal. Whilst the curves showed similar dipping behaviour, it was observed that towards the logarithmic ends of the curves, these two curves show different rates of increase. This particular rate of increase, coined as shear recovery, was observed to be higher for the $14,000 \mathrm{cP}$ ink compared to that of the $1,000 \mathrm{cP}$ ink. This higher recovery could explain the results shown in previous studies $[18,23]$ reporting that inks of higher viscosity show signs of less spreading. The higher rate of recovery could increase the resistance of the ink volume to flow and thereby produced thinner line widths.

From Fig. 11, it could be observed that through the addition of silver nanostructures, there were 2 distinct changes in the behaviour of the ink under the same set of shearing conditions. When subjected to higher shear rates, the formulation with silver nanostructures was observed to shear thin by a slight margin. However, in the event shear removal, there was a significant increase in the shear recovery. This would prove to be important as this formulation could potentially replace inks of higher viscosity. This formulation could reap the strengths of a high viscosity ink without incurring the drawbacks such as difficulties in proper doctoring of ink.

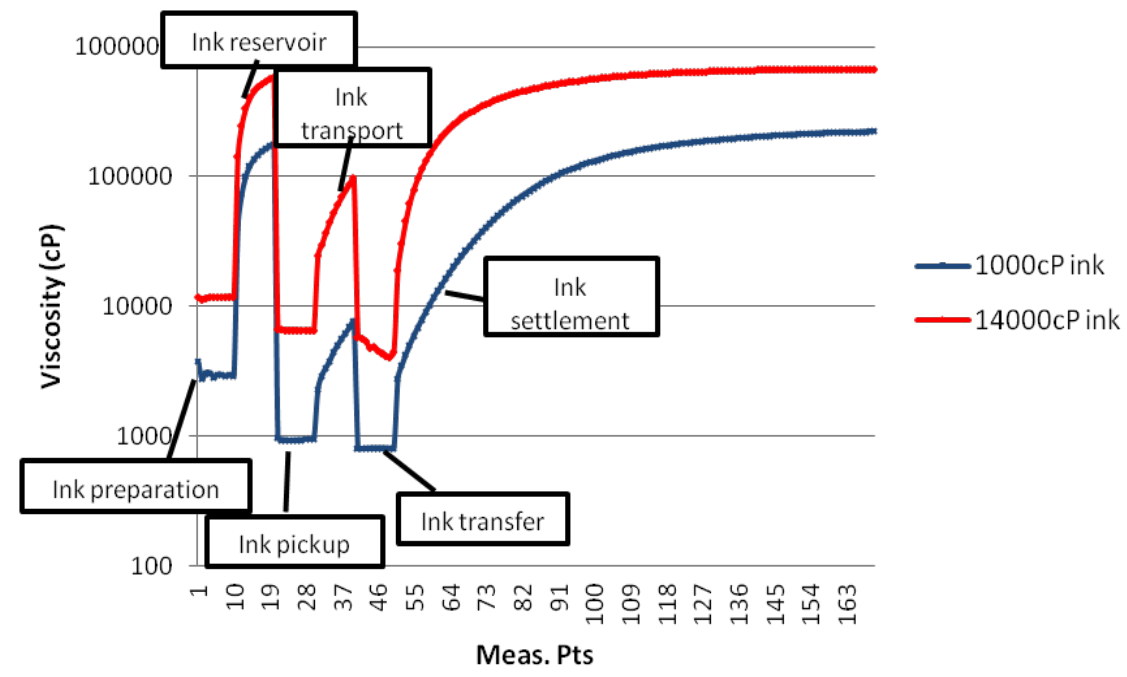

Fig. 10. Comparison of ink behavior under different shearing conditions between $14,000 \mathrm{cP}$ and $1,000 \mathrm{cP}$ ink. The logarithmic end of the $14,000 \mathrm{cP}$ ink curve shows a higher rate of increase than that of the 1,000 cP ink.

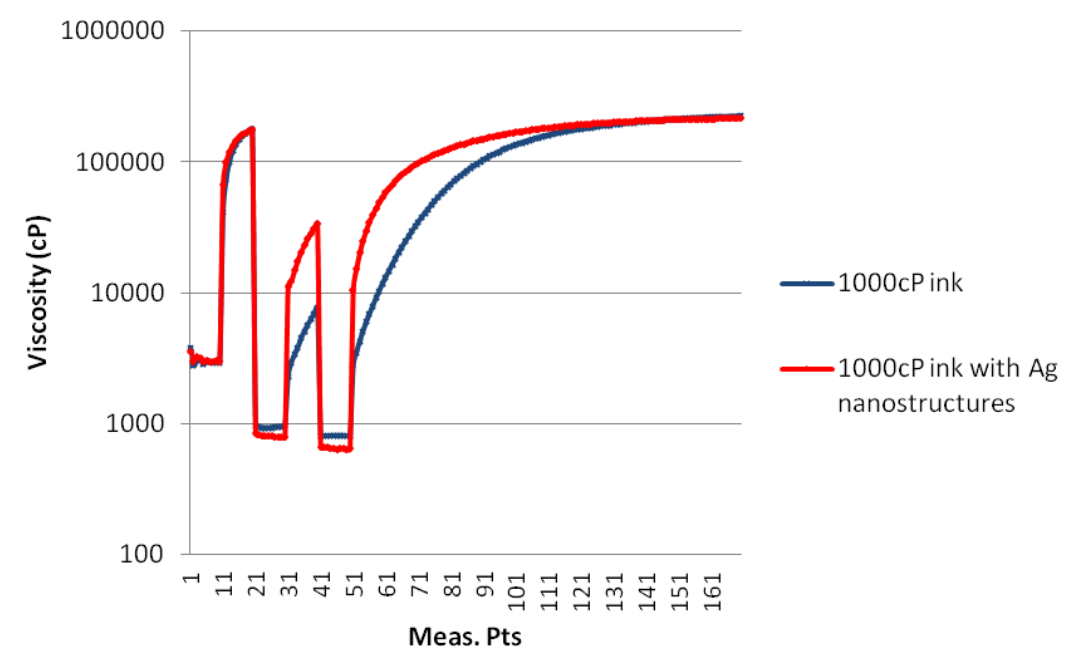

Fig. 11. Comparison of ink behavior under different shearing conditions between the 1,000 cP ink and the $1,000 \mathrm{cP}$ composite ink with silver nanostructures. The logarithmic end of the composite ink curve shows a higher rate of increase than that of the $1,000 \mathrm{cP}$ ink. 


\section{Conclusions}

This study has investigated the impacts of ink viscosity and printing speed on the printed line width. Fine line printing was realized without the need of specialized engraving. A 1:1 replication of the nominal line width has been achieved using an ink of a higher viscosity printed at $5 \mathrm{~m} / \mathrm{min}$. Ink viscosity and printing speed have shown to have significant effects on the printed ink particle distribution and size. The mass transfer ratio was developed to characterize ink transfer for printed lines more accurately, while the particle transfer ratio was developed to quantify the conduit transfer of the printing ink (conductive particles). The thixotropic properties and shear recovery behaviors of inks of different viscosities were also examined to investigate the mechanism behind the less spreading of a higher viscosity ink. Further reduction in printed line width over a large printing area could replace indium tin oxide as an optically transparent conductor to be used in smart devices. Further studies would be conducted to validate the effects of a composite ink on actual printed substrates.

\section{References}

[1] Schift H. Nanoimprint lithography: An old story in modern times? A review. Journal of Vacuum Science \& Technology B: Microelectronics and Nanometer Structures. 2008;26:458-480.

[2] Ahn SH, Guo LJ. Large-area roll-to-roll and roll-to-plate nanoimprint lithography: A step toward highthroughput application of continuous nanoimprinting. ACS Nano. 2009;3:2304-2310.

[3] Chou SY, Krauss PR, Renstrom PJ. Imprint of sub-25 nm vias and trenches in polymers. Applied Physics Letters. 1995;67:3114-3116.

[4] Zhong ZW, Shan XC, Yao YC. Investigation of antiadhesive coatings for nanoimprinting lithography. Materials and Manufacturing Processes. 2010;25:658-664.

[5] Zhong ZW, Shan XC, Wong SJ. Roll-to-roll large-format slot die coating of photosensitive resin for UV embossing. Microsystem Technologies. 2011;17:1703-1711.

[6] Zhong ZW, Ee JH, Chen SH, Shan XC. Parametric investigation of flexographic printing processes for R2R printed electronics. Materials and Manufacturing Processes. 2020;35:564-571.

[7] Lee T-M, Noh J-H, Kim I, Kim D-S, Chun S. Reliability of gravure offset printing under various printing conditions. Journal of Applied Physics. 2010;108:102802.

[8] Zhong ZW, Tang RWL, Chen SH, Shan XC. A study of screen printing of stretchable circuits on polyurethane substrates. Microsystem Technologies. 2019;25:339-350.

[9] Søndergaard RR, Hösel M, Krebs FC. Roll-to-Roll fabrication of large area functional organic materials. Journal of Polymer Science Part B: Polymer Physics. 2013;51:16-34.

[10] Zhong ZW, Shan XC. A study of meniscus formation and its effect on roll-to-roll UV embossing. International Journal of Engineering Science. 2014;85:10-19.

[11] Zhong ZW, Ng HH, Chen SH, Shan XC. Hot roller embossing of multi-dimensional microstructures using elastomeric molds. Microsystem Technologies. 2018;24:1443-1452.

[12] Rogers JA LH. Unconventional nanopatterning techniques and applications. Hoboken: John Wiley \& Sons; 2008.

[13] Zhong ZW, Shan XC, Lim YZ. The edge-effect on roll-to-roll thermal embossing of micro channels. Microsystem Technologies. 2015;21:1267-1273.

[14] Zhong ZW, Shan XC. Microstructure formation via roll-to-roll UV embossing using a flexible mould made from a laminated polymer-copper film. Journal of Micromechanics and Microengineering. 2012;22:085010.

[15] Kitsomboonloha R, Morris S, Rong X, Subramanian V. Femtoliter-scale patterning by high-speed, highly scaled inverse gravure printing. Langmuir. 2012;28:16711-16723.

[16] Kang H, Kitsomboonloha R, Jang J, Subramanian V. High-performance printed transistors realized using femtoliter gravure-printed sub-10 $\mu \mathrm{m}$ metallic nanoparticle patterns and highly uniform polymer dielectric and semiconductor layers. Advanced Materials. 2012;24:3065-3069.

[17] Benkreira H, Patel R. Direct gravure roll coating. Chemical Engineering Science. 1993;48:2329-2335.

[18] Kapur N. A parametric study of direct gravure coating. Chemical Engineering Science. 2003;58:2875-2882.

[19] Hewson RW, Kapur N, Gaskell PH. A two-scale model for discrete cell gravure roll coating. Chemical Engineering Science. 2011;66:3666-3674.

[20] Bohan MFJ, Claypole TC, Gethin DT. The effect of process parameters on product quality of rotogravure printing. Proceedings of the Institution of Mechanical Engineers, Part B: Journal of Engineering Manufacture. 2000;214:205-219.

[21] Lee S, Na Y. Analysis on the ink transfer mechanism in R2R application. Journal of mechanical science and technology. 2010;24:293-296.

[22] Lee J-W, Mun KK, Yoo YT. A comparative study on roll-to-roll gravure printing on PET and BOPP webs with aqueous ink. Progress in Organic Coatings. 2009;64:98-108. 
[23] Hrehorova E, Rebros M, Pekarovicova A, Bazuin B, Ranganathan A, Garner S, Merz G, Tosch J, Boudreau R. Gravure printing of conductive inks on glass substrates for applications in printed electronics. Journal of Display Technology. 2011;7:318-324.

[24] Secor EB, Lim S, Zhang H, Frisbie CD, Francis LF, Hersam MC. Gravure printing of graphene for largearea flexible electronics. Advanced Materials. 2014;26:4533-4538.

[25] Nguyen HAD, Lee J, Kim CH, Shin K-H, Lee D. An approach for controlling printed line-width in high resolution roll-to-roll gravure printing. Journal of Micromechanics and Microengineering. 2013;23:095010.

[26] Park J, Nguyen HAD, Park S, Lee J, Kim B, Lee D. Roll-to-roll gravure printed silver patterns to guarantee printability and functionality for mass production. Current Applied Physics. 2015;15:367-376.

[27] Hewson RW, Kapur N, Gaskell PH. A theoretical and experimental investigation of tri-helical gravure roll coating. Chemical Engineering Science. 2006;61:5487-5499.

[28] Sankaran AK, Rothstein JP. Effect of viscoelasticity on liquid transfer during gravure printing. Journal of Non-Newtonian Fluid Mechanics. 2012;175-176:64-75.

[29] Hewson RW, Kapur N, Gaskell PH. Tri-helical gravure roll coating. Chemical Engineering Science. 2010;65:1311-1321.

[30] Kim S, Sung HJ. Effect of printing parameters on gravure patterning with conductive silver ink. Journal of Micromechanics and Microengineering. 2015;25:045004.

[31] Phillies GDJ. Phenomenology of polymer solution dynamics. Cambridge: Cambridge University Press; 2011.

[32] Voigt MM, Mackenzie RCI, King SP, Yau CP, Atienzar P, Dane J, Keivanidis PE, Zadrazil I, Bradley DDC, Nelson J. Gravure printing inverted organic solar cells: The influence of ink properties on film quality and device performance. Solar Energy Materials and Solar Cells. 2012;105:77-85.

[33] Park JD, Lim S, Kim H. Patterned silver nanowires using the gravure printing process for flexible applications. Thin Solid Films. 2015;586:70-75.

[34] Oliveira ISSd, Otter WKd, Briels WJ. Alignment and segregation of bidisperse colloids in a shear-thinning viscoelastic fluid under shear flow. EPL (Europhysics Letters). 2013;101:28002.

(C) 2020 by the author(s). This work is licensed under a Creative Commons Attribution 4.0 International License (http://creativecommons.org/licenses/by/4.0/). Authors retain copyright of their work, with first publication rights granted to Tech Reviews Ltd. 